\title{
GAME EDUKASI PENGENALAN BUAH-BUAHAN BERVITAMIN C UNTUK ANAK USIA DINI
}

\author{
Ferdi Yulianto ${ }^{1}$, Yohana Tri Utami ${ }^{2}$, Imam Ahmad ${ }^{3}$ \\ Fakultas Teknik dan Ilmu Komputer \\ UniversitasTeknokrat Indonesia \\ ferdiyulianto1@gmail.com ${ }^{1}$, yohana.triutami@gmail.com ${ }^{2}$, imamahmad@teknokratl.ac.id ${ }^{3}$
}

\begin{abstract}
Abstrak
Game adalah permainan yang dibuat dengan tujuan pembelajaran yang bukan hanya bermaksud menghibur tetapi juga diharapkan bisa menambah wawasan pengetahuan. Dalam ilmu botani buah adalah organ pada tumbuhan berbunga yang merupakan modifikasi lanjut bakal buah (ovarium). Vitamin $\mathrm{C}$ adalah salah satu jenis vitamin yang larut dalam air dan memiliki peranan penting dalam menangkal berbagai penyakit.Vitamin ini juga dikenal dengan nama kimia dari bentuk utamanya yaitu asam askorbat. Metode pengembangan sistem yang digunakan adalah metode MDLC (Multimedia Development Life Cycle). Aplikasi yang digunakan dalam pembuatan game ini adalah Construct 2. Metode pengujian yang digunakan adalah pengujian ISO 9126 (usability, fungtionality, portability). Hasil pengujian kualitas aspek functionality oleh 3 (tiga) orang yang ahli di bidang software engineering menunjukan bahwa aplikasi dapat melakukan semua fungsinya dengan benar sehingga kualitas perangkat lunak $100 \%$ valid. Hasil pengujian kualitas aspek portability menunjukan bahwa aplikasi tersebut dapat berjalan pada device android minimal Kitkat. Hasil pengujian kualitas aspek usability oleh 30 anak usia dini pada TK Aisyiyah Bustanul Athfal III, game edukasi Pengenalan Buah-buahan Bervitamin C memperoleh nilai $85 \%$. Berdasarkan hasil dari beberapa pengujian yang telah dilakukan menunjukkan bahwa aplikasi game tersebut dapat digunakan oleh anak usia dini sebagai media sarana hiburan dan dapat meningkatkan minat belajar anak untuk belajar mengenal Buah-buahan khususnya yang mengandung vitamin $\mathrm{C}$.
\end{abstract}

Kata kunci: Game, Buah-Buahan, Vitamin C, Anak Usia Dini.

\begin{abstract}
Games are games that are made with learning goals that not only mean to entertain but are also expected to increase knowledge. In botany the fruit is an organ in flowering plants which is a further modification of the ovaries. Vitamin $\mathrm{C}$ is a type of vitamin that is water soluble and has an important role in warding off various diseases. This vitamin is also known by the chemical name of its main form, ascorbic acid. The system development method used is the MDLC (Multimedia Development Life Cycle) method. The application used in making this game is Construct 2. The testing method used is testing ISO 9126 (usability, functionality, portability). The results of functionality aspect quality testing by 3 (three) people who are experts in the field of software engineering show that the application can perform all its functions correctly so that the software quality is $100 \%$ valid. The results of testing the quality of portability aspects indicate that the application can run on a minimum Android device Kitkat. The results of testing the quality of the usability aspect by 30 early childhood children at Aisyiyah Bustanul Athfal III kindergarten, Vitamin C Introduction to the educational game C obtained a value of $85 \%$. Based on the results of several tests that have been conducted show that the game application can be used by early childhood as a medium of entertainment facilities and can increase children's learning interest to learn to know Fruits, especially those containing vitamin $\mathrm{C}$.
\end{abstract}

Keywords: Games, Fruits, Vitamin C, Early Childhood. 


\section{PENDAHULUAN}

\section{A. LATAR BELAKANG}

\begin{abstract}
Game merupakan aktifitas terstruktur atau semi terstruktur yang biasanya bertujuan untuk hiburan dan kadang dapat digunakan sebagai sarana pendidikan. Karakterisitik game yang menyenangkan, memotivasi, membuat kecanduan dan kolaboratif membuat aktifitas ini digemari oleh banyak orang, Dalam ilmu botani buah adalah organ pada tumbuhan berbunga yang merupakan modifikasi lanjut bakal buah (ovarium). Vitamin $\quad \mathrm{C}$ adalah salah satu
\end{abstract} jenis vitamin yang larut dalam air dan memiliki peranan penting dalam menangkal berbagai penyakit.

Anak usia dini adalah anak yang berada pada rentan usia 0-6 tahun (Undang-undang Sidiknas tahun 2003) dan 0-8 tahun menurut para pakar pendidikan. Untuk mempermudah dalam pengenalan buah-buahan yang mengandung vitamin $C$ pada anak-anak usia dini, maka dalam penelitian ini akan dikembangkan sebuah game edukasi berbasis android yang dapat menambah wawasan anak-anak usia dini dalam belajar dan bermain.

Android merupakan sebuah sistem operasi perangkat mobile berbasis linux yang mencakup sistem operasi, middlewere, dan aplikasi. Menurut widodo dan ahmad (2018) android dapat digunakan untuk sebuah permainan atau game baik itu yang bersifat edukasi atau petualangan. Sedangkan menurut mohamad dkk (2017) android dapat diguanakan dalam bidang pariwisata seperti pemetaan pada suatu wilayah. Penulis ingin merancang sebuah game berbasis android sebagai media pembelajaran untuk anak usia dini. Game yang akan dirancang merupakan game edukasi yang berlatar belakang buahbuahan, dalam pengembangannya nanti game bergenre casual, dimana nantinya pada game ini akan memperkenalkan buahbuahan apa saja yang mengandung vitamin C yang akan dibuat dengan konsep puzzle didalam game tersebut. Dimana nantinya sebelum kita memainkan game tersebut kita akan dikenalkan terlebih dahulu tentang buuah-buahan yang mengandung vitamin $C$, dan dalam game ini terdapat 4 jenis permainan yaitu tebak buah, puzzle buah, acak kata dan tebak bentuk.

A. Rumusan Masalah

Berdasarkan latar belakang yang dijelaskan maka, dapat disimpulkan dalam rumusan masalah sebagai berikut:

1. Bagaimana membuat game edukasi Buah-buahan bervitamin C bagi anak usia dini ?

2. Bagaimana tingkat pemahaman siswa mengenai buah bervitamin $C$ yang diukur menggunakan kuisioner?

B. Batasan Masalah

Batasan masalah penelitian dimaksudkan agar penelitian yang dilakukan akan terfokus pada pokok bahasan yang ditentukan saja. Adapun batasan masalah yang dibahas dalam penelitian ini adalah sebagai berikut:

1. Penelitian ini hanya membahas mengenai 20 buah-buahan yang memiliki Vitamin $\mathrm{C}$ terbanyak .

2. Pengguna utama Game edukasi pengenalan buah-buahan bervitamin c ini adalah anakanak usia dini.

3. Software yang digunakan untuk membuat game edukasi ini adalah Construct 2 atau aplikasi berbasis HTML 5 yang dikhususkan untuk plafform 2D.

C. Tujuan Penelitian

Adapun tujuan dari dilakukannya penelitian adalah sebagai berikut:

1. Membuat game pengenalan buah bervitamn $\mathrm{C}$ bagi anak usia dini.

2. Mengukur tingkat pemahaman siswa mengenai buah-buahan yang mengandung vitamin $\mathrm{C}$.

D. Manfaat Penelitian

Adapun manfaat dari dilakukannya penelitian ini adalah sebagai berikut: 
1. Sebagai media hiburan dan edukasi bagi anak-anak usia dini.

2. Sebagai salah satu media yang dapat mengenalkan buahbuahan yang mengandung vitamin C.

\section{B. ARTIKEL TERKAIT}

Beberapa penelitian yang terkait dengan aplikasi game edukasi pengenalan buah-buahan bervitamin $\mathrm{C}$ untuk anak usia dini diantaranya penelitian yang dilakukan Putra, D.W., dkk tahun 2016 dengan penelitian yang berjudul Game Edukasi Berbasis Android Sebagai Media Pembelajaran Untuk Anak Usia Dini. Dimana pada penelitian yang dilakukan penulis adalah game untuk mengasah daya fikir dan logika yang dapat memperkenalkan materi agar lebih menarik untuk diterima dan dipahami terutama oleh anak yang masih dalam usia dini. Anak usia dini antara umur 3- 6 tahun beraca dalam masa Golden Periode (Periode Keemasan) perkembangan otak mereka. Dalam usia ini, mereka berada pada masa pertumbuhan dan perkembangan yang paling pesat baik fisik maupun mental(sumber: TK Hidayatullah). Game edukasi yang tercipta mengajarkan tentang pengembangan daya pikir dan daya cipta yang meliputi pembelajaran mengenal bunatang, lagu-lagu anak, mewarnai dan alphabet serta didukung dengan antarmuka yang mudah dimengerti dan dioperasikan oleh anak usia dini 3-6 tahun. Game edukasi ini telah diuji dengan menggunakan metode pengujian White Box Testing dan Black Box Testing.

Penelitian dilakukan oleh Irsa, D., dkk tahun 2015 dengan penelitian berjudul Perancangan Aplikasi Game Edukasi Pembelajaran Anak Usia Dini Menggunakan Linear Congruent Method (LCM) Berbasis Android. Dimana dalam penelitian yang dilakukan oleh peneliti mengangkat masalah bagaimana membangun game edukasi calistung untuk anak usia dini umur 3-8 tahun berbasis android yang menarik dan interaktif agar proses belajar lebih menyenangkan dan minat belajar anak meningkat serta materi calistung yang di terapkan mudah diserap dan dimengerti oleh anak dengan bimbingan orang tua dan guru.

Penelitian dilakukan oleh Adiwijaya, M., dkk tahun 2015 dengan penelitian berjudul Perancangan Game Edukasi Platform Belajar Matematika Berbasis Android Menggunakan Construct 2. Dimana dalam penelitian yang dilakukan penulis mengangkat permasalahan tentang bagaimana memudahkan anak anak dalam memahami dan mempelajari pelajaran matematika dengan memanfaatkan game edukasi. Untuk meningkatkan minat belajar maka dirancanglah sebuah game dengan memanfaatkan software construct 2. Dalam pengujiannya aplikasi diuji dengan menggunakan metode black box dengan hasil yaitu aplikasi game edukasi ini dapat dipasang pada smartphone.

\section{METODE PENELITIAN}

\subsection{Kerangka Pemikiran}

Kerangka pemikiran merupakan bentuk dari keseluruan proses dalam penelitian. Diawali dengan identifikasi masalah, kemudian usulan solusi, dilanjutkan ke tahap pengembangan, mendapatkan hasil pembahasan dan kesimpulan. Adapun kerangka pemikiran dari penelitian ini dapat dilihat pada gambar.

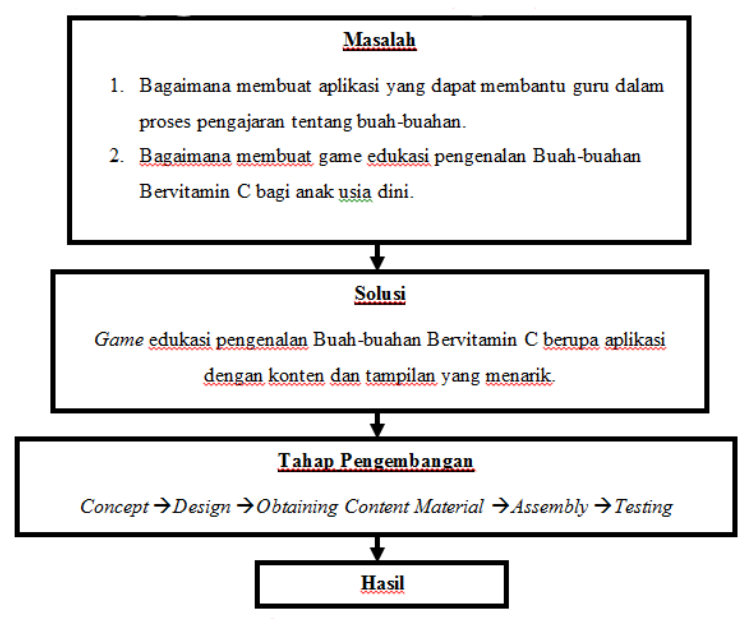

Gambar 3.1. Kerangka Pemikiran

\section{Flowchart view}

Dalam aplikasi game ini flowchart view digunakan untuk menggambarkan alur 
program. Flowchart view dapat dilihat pada gambar 3.2.

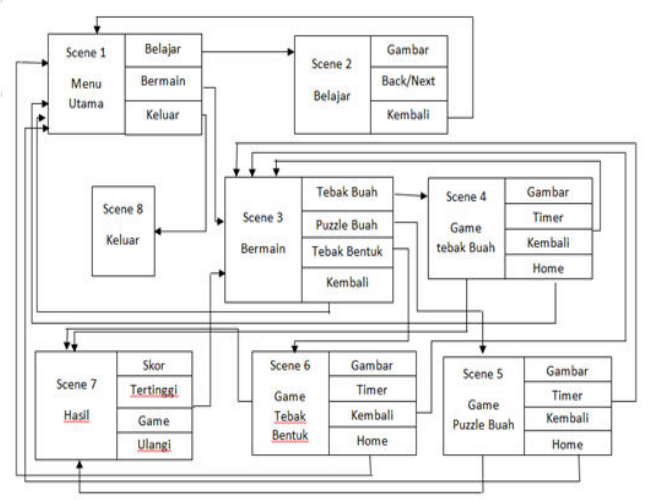

Gambar 3.2 Flowchart view

\section{Aspek Usability}

Untuk pengujian aspek usability di penelitian ini menggunakan kuisioner yang diisi oleh pemain game (gamer). Berikut daftar pertanyaannya:

Tabel 3.5 Kisi-kisi pernyataan aspek usability

\begin{tabular}{|c|c|c|}
\hline No & Kriteria & Pernyataan \\
\hline 1 & \multirow[t]{4}{*}{ Operability } & $\begin{array}{l}\text { Cara } \\
\text { menggunakan } \\
\text { game sangat } \\
\text { sederhana. }\end{array}$ \\
\hline 2 & & $\begin{array}{l}\text { Saya belajar untuk } \\
\text { menggunakan } \\
\text { aplikasi ini dengan } \\
\text { cepat. }\end{array}$ \\
\hline 3 & & $\begin{array}{l}\text { Saya dapat } \\
\text { menggunakan } \\
\text { game ini tanpa } \\
\text { instruksi tertulis. }\end{array}$ \\
\hline 4 & & $\begin{array}{l}\text { Secara } \\
\text { keseluruhan, saya } \\
\text { puas dengan } \\
\text { kemudahan } \\
\text { penggunaan } \\
\text { game ini. }\end{array}$ \\
\hline \multirow[t]{2}{*}{5} & \multirow[t]{2}{*}{ Learnability } & $\begin{array}{l}\text { Aplikasi game } \\
\text { cocok untuk anak } \\
\text { usia dini. }\end{array}$ \\
\hline & & $\begin{array}{lr}\text { Aplikasi } & \text { game } \\
\text { dapat } & \text { membantu } \\
\text { untuk mengenal }\end{array}$ \\
\hline
\end{tabular}

\begin{tabular}{|c|c|c|}
\hline & & $\begin{array}{l}\text { buah-buahan } \\
\text { bervitamin C }\end{array}$ \\
\hline 7 & \multirow[t]{2}{*}{ Understandability } & $\begin{array}{l}\text { Informasi dalam } \\
\text { aplikasi mudah } \\
\text { untuk dipahami }\end{array}$ \\
\hline 8 & & $\begin{array}{l}\text { Informasi yang } \\
\text { disediakan mudah } \\
\text { untuk membantu } \\
\text { menyelesaikan } \\
\text { game ini. }\end{array}$ \\
\hline 9 & \multirow[t]{5}{*}{ Attractiveness } & $\begin{array}{l}\text { Tampilan game ini } \\
\text { menyenangkan. }\end{array}$ \\
\hline 10 & & $\begin{array}{l}\text { Aplikasi game } \\
\text { dapat merespon } \\
\text { dengan baik. }\end{array}$ \\
\hline 11 & & $\begin{array}{l}\text { Kesesuaian icon } \\
\text { dengan } \\
\text { background } \\
\text { bagus. }\end{array}$ \\
\hline 12 & & $\begin{array}{l}\text { Kesesuaian warna } \\
\text { pada aplikasi } \\
\text { bagus. }\end{array}$ \\
\hline 13 & & $\begin{array}{l}\text { Secara } \\
\text { keseluruhan, saya } \\
\text { puas dengan } \\
\text { game ini. }\end{array}$ \\
\hline
\end{tabular}

\section{Aspek Funcionality}

Untuk pengujian aspek functionality menggunakan kuesioner yang berisi daftar fungsi yang dimiliki aplikasi. Kuisioner diisi oleh 3 orang yang memiliki keahlian dalam bidang software engineering.

Table 3.6 kisi-kisi pertanyaan aspek functionality

\begin{tabular}{|r|l|l|l|}
\hline \multicolumn{2}{|c|}{ Pernyataan } & \multicolumn{2}{c|}{ Hasil } \\
\hline \multicolumn{2}{|c|}{ A. Suitability } & Sukses & Gagal \\
\hline 1 & \multicolumn{1}{|c|}{$\begin{array}{l}\text { Menampilkan Menu } \\
\text { Utama }\end{array}$} & & \\
\hline 2 & $\begin{array}{l}\text { Tombol Belajar Pada } \\
\text { Menu Utama }\end{array}$ & & \\
\hline 3 & $\begin{array}{l}\text { Tombol Bermain Pada } \\
\text { Menu Utama }\end{array}$ & & \\
\hline 4 & $\begin{array}{l}\text { Tombol Sound Pada } \\
\text { Menu Utama }\end{array}$ & & \\
\hline 5 & $\begin{array}{l}\text { Tombol Tentang pada } \\
\text { Menu utama }\end{array}$ & & \\
\hline
\end{tabular}




\begin{tabular}{|c|c|c|c|}
\hline 6 & $\begin{array}{l}\text { Tombol keluar pada } \\
\text { menu utama }\end{array}$ & & \\
\hline \multicolumn{2}{|c|}{ B. Accuracy } & Sukses & Gagal \\
\hline 1 & $\begin{array}{l}\text { Menampilkan } \\
\text { Halaman Tentang }\end{array}$ & & \\
\hline 2 & $\begin{array}{l}\text { Menampilkan } \\
\text { Halaman Belajar }\end{array}$ & & \\
\hline 3 & $\begin{array}{l}\text { Menampilkan } \\
\text { Halaman Bermain }\end{array}$ & & \\
\hline 4 & $\begin{array}{l}\text { Tombol Home pada } \\
\text { halaman menu Belajar }\end{array}$ & & \\
\hline 5 & $\begin{array}{l}\text { Tombol next dan back } \\
\text { pada halaman menu } \\
\text { Belajar }\end{array}$ & & \\
\hline 6 & $\begin{array}{l}\text { Tombol Home pada } \\
\text { halaman menu } \\
\text { Bermain }\end{array}$ & & \\
\hline 7 & $\begin{array}{l}\text { Tombol game tebak } \\
\text { bentuk pada menu } \\
\text { bermain }\end{array}$ & & \\
\hline 8 & $\begin{array}{l}\text { Tombol game tebak } \\
\text { buah pada menu } \\
\text { bermain }\end{array}$ & & \\
\hline 9 & $\begin{array}{l}\text { Tombol game puzzle } \\
\text { buah pada menu } \\
\text { bermain }\end{array}$ & & \\
\hline 10 & $\begin{array}{l}\text { menampilkan popup } \\
\text { keluar }\end{array}$ & & \\
\hline \multicolumn{2}{|c|}{ C. Interoperability } & Sukses & Gagal \\
\hline 1 & $\begin{array}{l}\text { Tombol home pada } \\
\text { game tebak bentuk }\end{array}$ & & \\
\hline 2 & $\begin{array}{l}\text { Tombol back pada } \\
\text { game tebak bentuk }\end{array}$ & & \\
\hline 3 & $\begin{array}{l}\text { Tombol bantuan pada } \\
\text { game tebak bentuk }\end{array}$ & & \\
\hline 4 & $\begin{array}{l}\text { time berjalan pada } \\
\text { game tebak bentuk }\end{array}$ & & \\
\hline 5 & $\begin{array}{l}\text { objek dapat di drag } \\
\text { and drop }\end{array}$ & & \\
\hline 6 & $\begin{array}{l}\text { Menampilkan hasil } \\
\text { game tebak bentuk }\end{array}$ & & \\
\hline 7 & $\begin{array}{l}\text { Tombol home pada } \\
\text { game tebak buah }\end{array}$ & & \\
\hline 8 & $\begin{array}{l}\text { Tombol back pada } \\
\text { game tebak buah }\end{array}$ & & \\
\hline 9 & $\begin{array}{l}\text { Tombol bantuan pada } \\
\text { game tebak buah }\end{array}$ & & \\
\hline
\end{tabular}

\begin{tabular}{|c|l|l|l|}
10 & $\begin{array}{l}\text { time berjalan pada } \\
\text { game tebak buah }\end{array}$ & & \\
\hline 11 & $\begin{array}{l}\text { objek buah dapat di } \\
\text { tekan }\end{array}$ & & \\
\hline 12 & $\begin{array}{l}\text { Menampilkan hasil } \\
\text { game tebak buah }\end{array}$ & & \\
\hline 13 & $\begin{array}{l}\text { Tombol home pada } \\
\text { game puzzle buah }\end{array}$ & & \\
\hline 14 & $\begin{array}{l}\text { Tombol back pada } \\
\text { game puzzle bauh }\end{array}$ & & \\
\hline 15 & $\begin{array}{l}\text { Tombol bantuan pada } \\
\text { game puzzle buah }\end{array}$ & & \\
\hline 16 & $\begin{array}{l}\text { time berjalan pada } \\
\text { game puzzle buah }\end{array}$ & & \\
\hline 17 & $\begin{array}{l}\text { objek dapat di drag } \\
\text { and drop }\end{array}$ & & \\
\hline 18 & $\begin{array}{l}\text { Menampilkan hasil } \\
\text { gamepuzzle buah }\end{array}$ & & \\
\hline
\end{tabular}

\section{Aspek Portability}

Untuk pengujian aspek portability menggunakan perangkat dengan OS Android versi Jelly Bean, Kitkat, Lolipop dan Marshmellow.

\section{HASIL DAN PEMBAHASAN}

\subsection{Implementasi Aplikasi}

Tahap implementasi merupakan tahap translasi desain yang telah dirancang ke dalam kode program, implementasi yang dilakukan meliputi implementasi rancangan antar muka (user interface). Sesuai dengan rancangan storyboard yang sudah dibuat, maka hasil implementasi rancangan interface adalah sebagai berikut:

\section{Menu Utama}

Halaman menu utama berisikan menu-menu yang bisa dipilih oleh pengguna. Halaman menu utama berisi menu Belajar, Permainan, exitkeluar, music, dan tentang game. Hasil implementasi menu utama dapat dilihat pada gambar 4.1 sebagai berikut: 


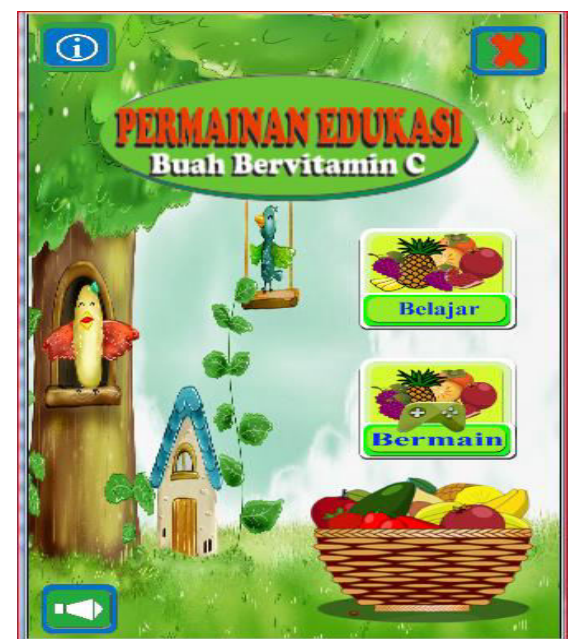

Gambar 4.1. Tampilan Menu Utama

\section{Menu Belajar}

Halaman menu belajar berisikan tentang informais buah-buahan yang mengandung vitamin C. Hasil implementasi menu belajar dapat dilihat pada gambar 4.2 sebagai berikut:

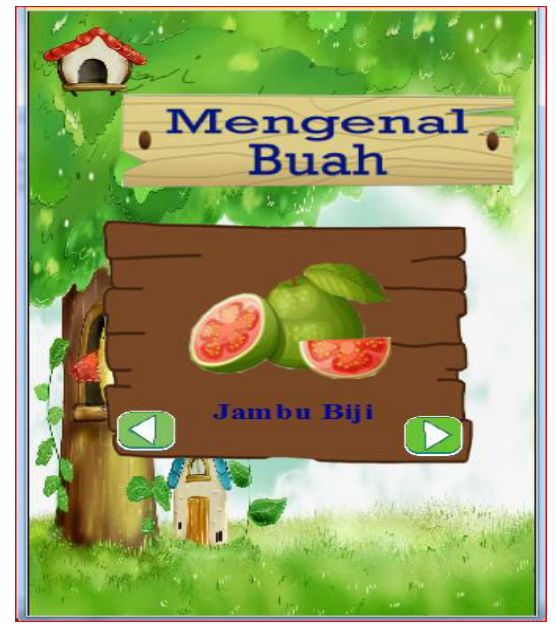

Gambar 4.2. Tampilan menu Belajar

\section{Tampilan menu Bermain}

Halaman tampilan bermain ini berisi pilihan permainan dimana terdapat permainan tebak buah, tebak bentuk dan puzzle buah.. Hasil implementasi tampilan menu bermain dapat dilihat pada gambar 4.3 sebagai berikut:

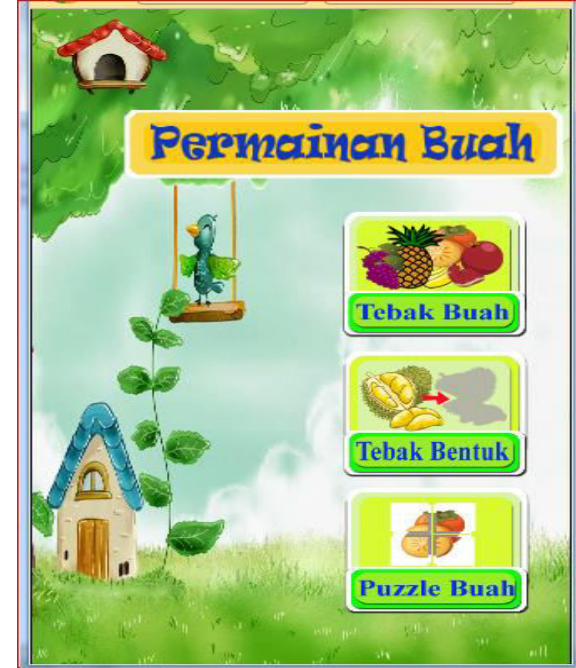

Gambar 4.3. Tampilan menu Bermain

4. Tampilan Permainan Tebak Buah Pada tampilan permainan tebak buah terdapat icon buah dan pilihan dari nama buah tersebut, pemain harus memilih gambar buah sesuai dengan yang diminta disoal tersebut. Berikut adalah gambar tampilan menu tebak buah dapat dilihat pada gambar 4.4

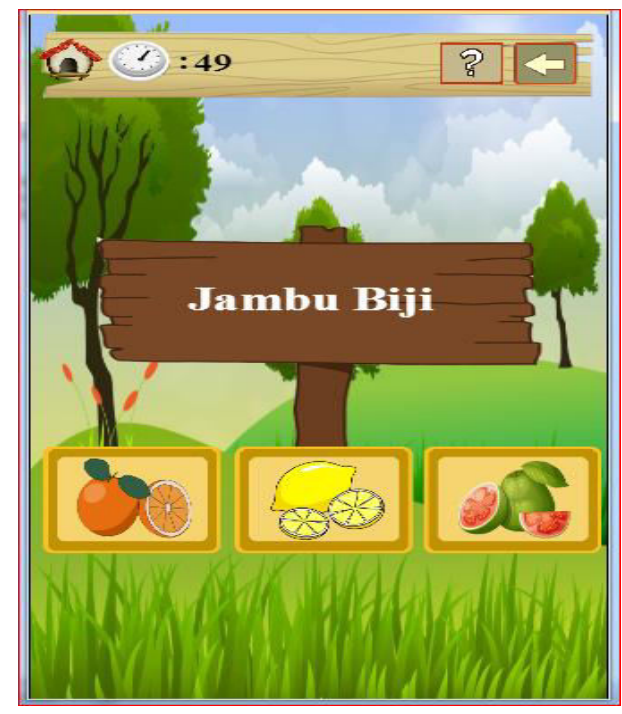

Gambar 4.4. Tampilan permainan tebak buah

\section{Tampilan Permainan Tebak Bentuk}

Pada tampilan menu tebak buah terdapat icon buah dan pilihan dari siluet yang ada. pemain disuruh untuk mencocokan gambar buah dengan siluet yang ada. Menu permainan tebak bentuk dapat diliha pada gambar 4.5 


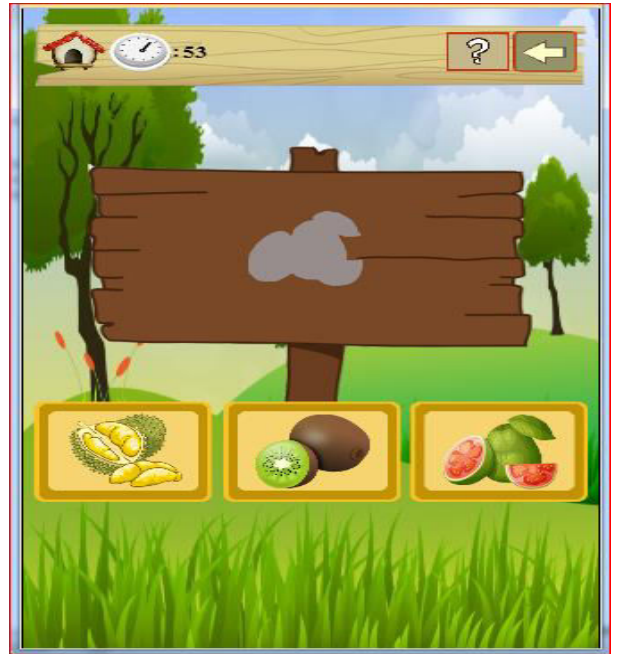

Gambar 4.5 Tampilan Menu Tebak Bentuk

\section{Tampilan Permainan Puzzle Buah}

Pada tampilan menu puzzle buah terdapat icon buah yang terpotong-potong, dan kemudian pemain harus menyesuaikan gambar yang telah disediakan yang kemudian di pasangkan agar menjadi sebuah gambar buah yang sempurna. Dapat dilihat pada gambar 4.6

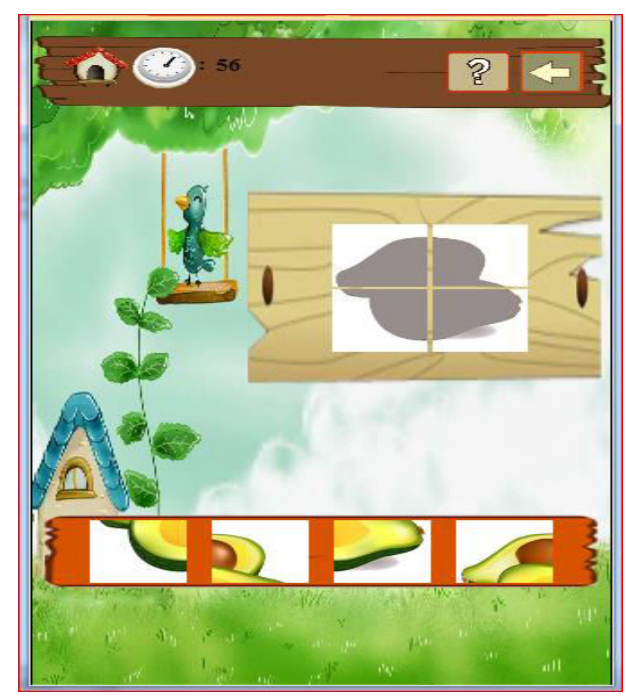

Gambar 4.6 Tampilan Permainan Puzzle Buah

\section{Tampilan Tentang Game}

Tampilan tentang merupakan tombol yang berfungsi untuk memberikan informasi mengenai aplikasi ini. Berikut tampilan menu tombol tentang dapat dilihat pada gambar 4.7

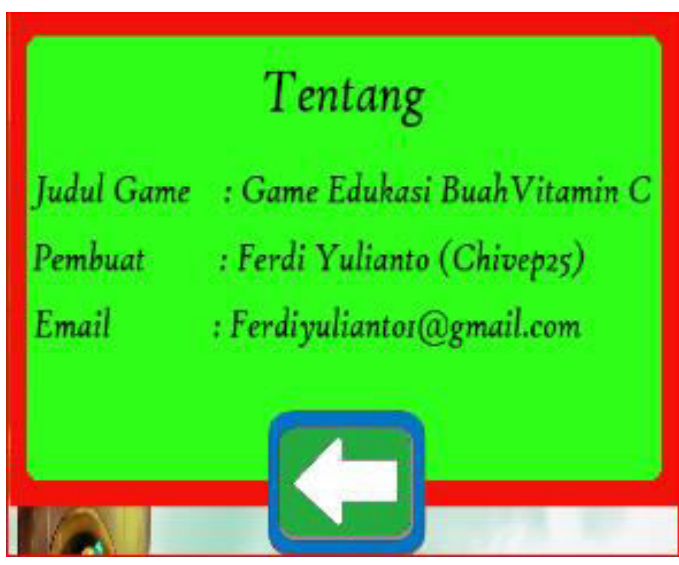

Gambar 4.7 Tampilan Tentang

\section{Tampilan Pop up Keluar Game} Tombol keluar merupakan tombol yang berfungsi untuk mengakhiri permainan. Tampilan menu popup keluar dapat dilihat pada gambar 4.8

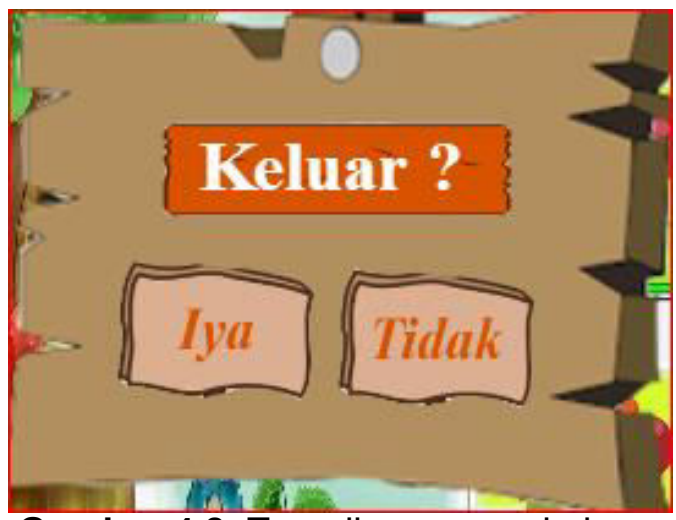

Gambar 4.8. Tampilan pop up keluar

\section{Tampilan Skor Permainan}

Tampilan hasil akhir pada setiap permainan. Dapat dilihat pada gambar 4.9

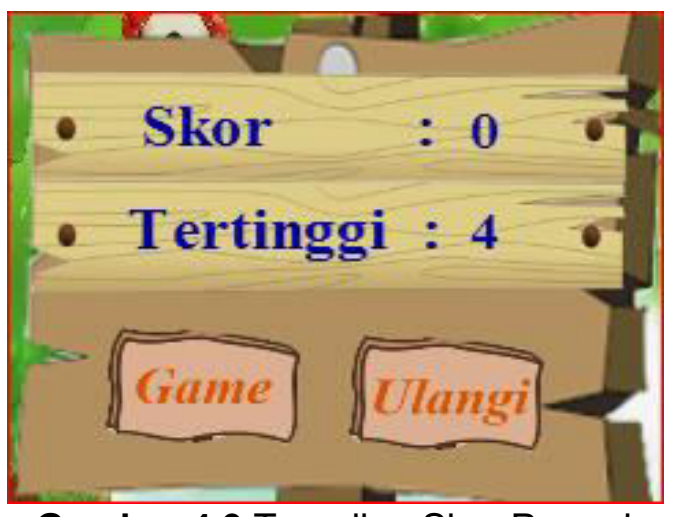

Gambar 4.9 Tampilan Skor Permainan 


\subsection{Hasil Pengujian ISO 9126}

Berdasarkan rencana pengujian aplikasi yang telah disusun, maka dilakukan beberapa tahap pengujian sebagai berikut.

a. Hasil Pengujian Usability

Pengujian aspek usability dilakukan terhadap anak usia dini di TK Aisyiyah Busthanul Athfal III ada 30 responden yang menilai aplikasi game ini, responden mencoba aplikasi game edukasi Pengenalan Buah-buahan bervitamin C pada device yang sudah disediakan kemudian responden mengisi kuesioner. Jumlah pernyataan dalam kuesioner tersebut 15 pernyataan yang didalamnya terdapat 4 sub aspek yaitu, operability, learnability, understandability, attractiveness dengan menggunakan skala $S S=5, S=4$, $\mathrm{N}=3$, TS $=2$, STS. Ada 30 responden yang menilai aplikasi game ini, responden mencoba aplikasi pada device yang sudah disediakan kemudian responden mengisi kuesioner. Diperoleh persentase sebesar $85 \%$ dari pengujian usability. Hasil itu didapat dari perhitungan:

$$
\begin{gathered}
\text { Persentase usability }=\frac{\text { total skor hasil pengujian }}{\text { skor tertinggi }} \times 100 \% \\
=\frac{1921}{2250} \times 100 \%=85 \%
\end{gathered}
$$

Hasil perhitungan yang didapatkan selanjutnya dibandingkan dengan rentang kriteria interpretasi skor dengan rentang seperti pada table 5.1

Table 5.1 Rentang Kriteria

\begin{tabular}{|c|c|c|}
\hline No & $\begin{array}{c}\text { Rentang } \\
\text { Kriteria }\end{array}$ & Kriteria \\
\hline 1 & $0 \%-20 \%$ & Sangat Tidak Layak \\
\hline 2 & $21 \%-40 \%$ & Tidak Layak \\
\hline 3 & $41 \%-60 \%$ & Kurang Layak \\
\hline 4 & $61 \%-80 \%$ & Layak \\
\hline 5 & $81 \%-100 \%$ & Sangat Layak \\
\hline
\end{tabular}

a. Hasil Pengujian Functionality

Pada pengujian functionality, kuesioner diisi oleh dua orang yang memiliki keahlian dalam bidang software engineering untuk mengetahui apakah fungsi-fungsi pada game dapat berjalan dengan benar. Diperoleh skor persentase $100 \%$ dari pengujian functionality yang artinya aplikasi dapat menjalankan seluruh fungsi dengan benar.

\section{b. Hasil Pengujian Portability}

Pada pengujian portability, dilakukan pada lima smartphone android dengan versi gingerbread, Jelly Bean, Kitkat, Lollipop dan Marshmellow untuk mengetahui apakah aplikasi dapat dijalankan pada berbagai macam smartphone dengan versi android yang berbeda, ditunjukan pada Tabel 5.2 .

\begin{tabular}{|c|c|c|c|c|}
\hline $\begin{array}{l}\mathbf{N} \\
\mathbf{O}\end{array}$ & $\begin{array}{c}\text { Jenis } \\
\text { Devic } \\
\text { e }\end{array}$ & $\begin{array}{l}\text { Jenis } \\
\text { Android }\end{array}$ & $\begin{array}{c}\text { Proses } \\
\text { Instalas } \\
\mathbf{i}\end{array}$ & $\begin{array}{l}\text { Proses } \\
\text { Running } \\
\text { Aplikasi }\end{array}$ \\
\hline 1 & $\begin{array}{c}\text { Lenov } \\
\text { o } \\
\text { A369i }\end{array}$ & $\begin{array}{l}4.2 .2 \\
\text { (Jelly } \\
\text { Bean) }\end{array}$ & $\begin{array}{l}\text { Instalasi } \\
\text { berhasil }\end{array}$ & $\begin{array}{c}\text { tampilan } \\
\text { tidak } \\
\text { berjalan } \\
\text { dengan baik } \\
\text { (menampilk } \\
\text { an screen } \\
\text { hijau) } \\
\end{array}$ \\
\hline 2 & $\begin{array}{l}\text { Asus } \\
\text { Z007 }\end{array}$ & $\begin{array}{c}4.4 .2 \\
\text { (Kitkat) }\end{array}$ & $\begin{array}{l}\text { Instalasi } \\
\text { berhasil }\end{array}$ & $\begin{array}{c}\text { Berjalan } \\
\text { baik tanpa } \\
\text { ada pesan } \\
\text { kesalahan } \\
\text { (error) }\end{array}$ \\
\hline 3 & Sony & $\begin{array}{c}5.0 .2 \\
\text { (Lolipop } \\
\text { ) }\end{array}$ & $\begin{array}{l}\text { Instalasi } \\
\text { berhasil }\end{array}$ & $\begin{array}{c}\text { Berjalan } \\
\text { baik tanpa } \\
\text { ada pesan } \\
\text { kesalahan } \\
\text { (error) }\end{array}$ \\
\hline 4 & $\begin{array}{l}\text { Xiomi } \\
4 a\end{array}$ & $\begin{array}{l}6.0 .1 \\
\text { (marsh } \\
\text { mellow) }\end{array}$ & $\begin{array}{l}\text { Instalasi } \\
\text { berhasil }\end{array}$ & $\begin{array}{l}\text { Berjalan } \\
\text { baik tanpa } \\
\text { ada pesan } \\
\text { kesalahan } \\
\text { (error) }\end{array}$ \\
\hline
\end{tabular}

Table 5.2 Pengujian Portability

\section{Penutup}

\subsection{Kesimpulan}

Berdasarkan uraian dan hasil yang telah dilakukan selama pembuatan game edukasi pengenalan buah-buahan 
bervitamin c untuk anak usia dini. Dapat diambil kesimpulan sebagai berikut :

1. Perancangan dan pembuatan aplikasi game edukasi ini bertujuan untuk menambah pengatahuan anak usia dini tentang buah-buahan khususnya yang mengandung vitamin c.

2. Berdasarkan hasil pengujian Usability pada aplikasi tersebut sebagai media belajar pengenalan buah pada platform android. Aplikasi dapat digunakan oleh anak usia dini dan orang tua murid untuk mengenalkan buah-buahan saat berada di rumah.

\subsection{Saran}

Saran yang dapat diberikan dalam pembuatan game edukasi pengenalan buah-buahan bervitamin c yaitu :

1. Game yang dibuat dapat dikembangkan lebih beragam lagi contohnya seperti desain, jenis buah dII

2. Semoga dengan adanya game ini akan muncul game edukasi lainnya yang lebih banyak membahas mengenai flora ataupun fauna khususnya yang ada di Indonesia.

\section{REFERENSI}

Adiwijaya, M. Imam S,K dan Christyono, Y., 2015, Perancangan Game Edukasi Platform Belajar Matematika Berbasis Android Menggunakan Construct 2. Jurusan Teknik Elektro Universitas Diponegoro Semarang, Semarang

Amanda Dwi, Galang., 2014, Pengukuran Kualitas untuk Aplikasi Permainan pada Perangkat Bergerak berdasarkan ISO 9126. Jurusan Teknik Informatika Institut Teknologi Sepuluh November, Surabaya

Astawan, Made. 2008. Sehat Dengan Buah. Penerbit Dian Rakyat. Jakarta
Binanto, Iwan., 2015, Tinjauan Metode Pengembanga Perangkat Lunak Multimedia Yang Sesuai

Untuk Mahasiswa Tugas Akhir. Teknik Informatika, Fakultas Sains dan Teknologi

Universitas Sanata Dharma, Yogyakarta, Indonesia

Chua, B. B., \& Dyson, L. E. 2004. Applying the ISO 9126 model to the evaluation of an elearning system. Beyond the comfort zone: Proceedings of the $21^{\text {st }}$ ASCILITE Conference, (pp. 184-190). Perth.

Davies MB, Austin J, Partridge DA. 1991. Vitamin C: Its Chemistry and Biochemistry. Hal : 97-100. The Royal Society of Chemistry: Cambridge

Dora Irsa, dkk. 2015. Perancangan Aplikasi Game Edukasi Pembelajaran Anak Usia Dini Menggunakan Linear Congruent Method (LCM) Berbasis Android. Universitas Indo Global Mandiri. Palembang.

Eva. (2009). Permainan Edukatif (Educational Games) Berbasis Komputer Untuk Siswa Sekolah Dasar. Malang. Sekolah Tinggi Informasi \& Komputer Indonesia.

Guritno, Suryo., Sudaryono \&Raharja Untung. 2011. Theory and apllication of IT research: Metodologi Penelitian Teknologi Informasi. Yogyakarta: Penerbit ANDI

Henry, F., Rees, T. and Tator, C., 2010. The colour of democracy: Racism in Canadian society. Nelson Education.

Irsa, D., Wiryasaputra, R., Primaini, S., 2015, Perancangan Aplikasi Game Edukasi Pembelajaran Anak Usia Dini Menggunakan Linear Congruent Method (LCM) Berbasis 
Android. Program Studi Informatika Universitas Indo Global Mandiri.

J. Von Neumann and O. Morgenstern, Theory of Games and Economic Behavior (3d ed. 1953)

Mansur. Pendidikan Anak Usia Dini dalam Islam. Yogyakarta: Pustaka Pelajar, 2005.

Permana, D. S. H., 2015 Perancangan Pembangunan Aplikasi Game Android Pengenalan Pola Warna Pada Paud Posdaya. Jurusan Teknik Informatika, Universitas Trilogi. Jakarta Selatan.

Priyatno, aris. 2014, Pengembangan Kreativitas Pada Anak Usia Dini Melalui Aktivitas Bermain Jurnal IImiah Gur. "COPE”, No. 02/Tahun XVIII/November 2014

Putra, D. W,. Nugroho A.P, dan Puspitarini,E. W., 2016 , Game Edukasi Berbasis Android Sebagai
Media Pembelajaran Untuk Anak Usia Dini. Program Studi Teknik Informatika, Fakultas Teknologi Informasi. Universitass Merdeka Pasuruan. Pasuruan.

Rozi, Zulfadli Fahrul. (2010). "Perancangan Game Mouse Hunter Menggunakan Adobe Flash CS

Sutopo, H. 2009. Pengembangan Model Pembelajaran Pembuatan Aplikasi Multimedia Khususnya Puzzle Game pada Mata Kuliah Multimedia. Disertasi (tidak diterbitkan). Jakarta: Universitas Negeri Jakarta.

Tian, Jeff. 2005. Software Quality Enginering: testing, quality assurance, and quantifiable impovement. John Wiley \& Sons, Inc. NewYork.

Vitianingsih, A. V., 2016. Game Edukasi Sebagai Media Pembelajaran Pendidikan Anak Usia Dini. Jurnal Inform Vol. 1. 